\title{
Performance of Reactive Routing Protocols DSR and AODV in Vehicular Ad-Hoc Networks Based on Quality of Service (Qos) Metrics
}

\author{
Cristian P. Saavedra Cañar, John J. Tucker Yépez, Heydi M. Roa López
}

\begin{abstract}
This article analyzes and compares the service quality metrics in reactive routing protocols AODV and DSR in VANET. Through the revision of the recorded information we study the characteristics, classification, applications and different traffic models. All these parameters are taken into account in the modelling of vehicular traffic in the downtown of Loja City. In order to get the corresponding results, three different scenarios each with a different node density have been created. According to the collected data, it is possible to verify which routing protocol is the most suitable for the Ad-Hoc networks proposed in this study.
\end{abstract}

Keywords: Ad-Hoc, AODV, Bonnmotion, Delay, DSR, Routing, Jitter, Manhattan Grid, Metrics, Mobility, NS-3, QoS, Throughput, VANET.

\section{INTRODUCTION}

The development of wireless networks and communication systems have had a positive impact on society, especially the evolution of mobile devices as they offer great mobility to users, together with a growing offer of communication devices such as smartphones, tablets and different mobile terminals that transform on a daily basis the way people communicate. [1]

Networks traditionally known as wireless have a device that manages the net and infrastructure making it possible to connect to different target devices. Nowadays, there is another concept in wireless networks known as Ad-Hoc or infrastructure-less network that allows the connection between terminals without a managing device. It means each existing user or node could perform as router, sender or receiver of data. [2]

One of the main targets in VANET is to assure the quality of service in the use of real-time applications as data or

Revised Manuscript Received on April 25, 2020.

* Correspondence Author

Cristian P. Saavedra Cañar*, Electronics and Telecommunications Engineer, Universidad Nacional de Loja, Ecuador, Department of Electronics and Telecommunications. cpsaavedrac@unl.edu.ec

John J. Tucker Yepez, Engineer specialist in communication networks and switching systems, Faculty of energy Researcher at the Universidad Nacional de Loja, Department of Telecommunications. jtucker@unl.edu.ec

Heydi M. Roa López, ESPOL Polytechnic University, Escuela Superior Politécnica del Litoral, ESPOL, Faculty of Natural Sciences and Mathematics. heydi.roa@gmail.com

(c) The Authors. Published by Blue Eyes Intelligence Engineering and Sciences Publication (BEIESP). This is an open access article under the CC BY-NC-ND license (http://creativecommons.org/licenses/by-nc-nd/4.0/) information transfer. This type of networks are well-known for being highly dynamic which causes the emergence of different topologies creating difficulties in discovering and keeping communication in the given scenarios. This brings as a result the loss of connectivity among vehicles causing a deterioration in service quality. [3]

Due to this problem, it is proposed to undertake a case study of two routing protocols used in Ad-Hoc networks, AODV and DSR. Quality of service metrics have been measured, compared and analyzed using the Ns-3 software to simulate the different scenarios and using Manhattan Grid as the mobility model.

\section{VANET (AD-HOC VEHICULAR NETWORK)}

VANET (Vehicular Ad-Hoc Network) allows the communication of several nodes using wireless links through ad-hoc networks. According to topology used, each node can act as a router communicating the generated data among the different target devices without direct connection between the source and the destination port. There is a growing interest in this type of networks especially in research oriented to work with government entities, the automotive industry and transportation sectors that care for safety and efficiency in the ground transportation system. In the research of these networks, traffic is monitored by different mobility models showing how vehicles move across the existing topology. [4][5]

In the first communication model, V2V (vehicle to vehicle) nodes exchange information directly between them through the use of on-board units (OBU). [6]

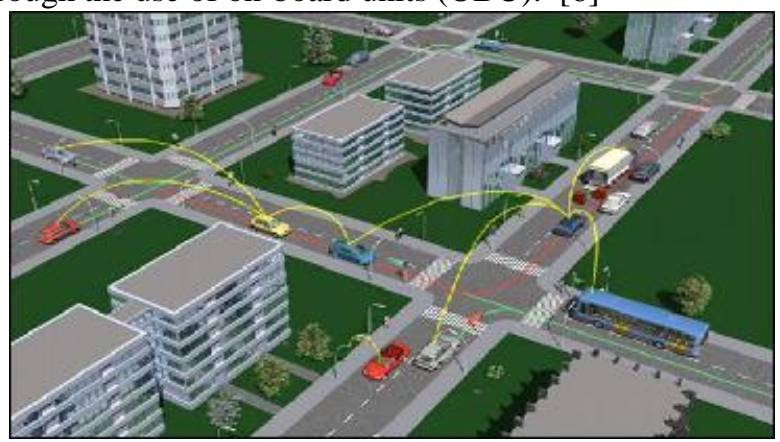

Figure 1- VANET V2V [3]

In the second communication model, vehicle to infrastructure, the interaction occurs through fixed devices that could be internet access points or servers placed along roads, tolls, etc. with units in specific points (RSURoad-Side Unit). [6]

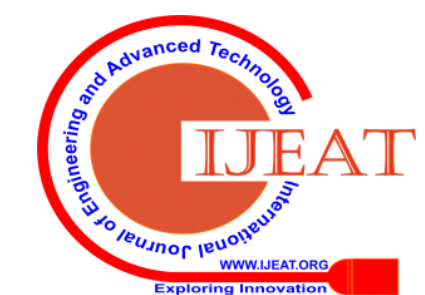




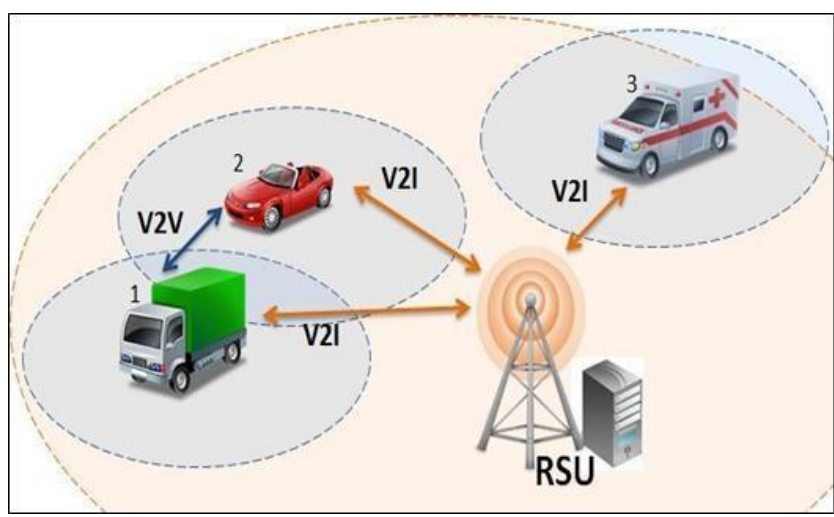

Figure 2- VANET V2I [6]

\section{A. VANET FEATURES}

The main features of VANET are:

Dynamic topology: As the nodes used on this network are in permanent movement and when predetermined patterns on the road are set, it leads to a fast-changing speed.

- Autonomy: Each node works in an autonomous way managing the information sent by the whole network. This network has no infrastructure so the information is sent to all the nodes allowing it to support communication failures.

- Distributed routing: The fact that nodes are autonomous allows them to distribute information to their neighbors.

- Unlimited energy: As the nodes are placed within the vehicles, their sensors receive energy constantly.

- Larger network: Networks are set all over the road axis generating a high number of nodes so the reception range needs to be extended.

\section{B. VANET LIMITATIONS}

VANET experiences some limitations during the implementation process and they are described below to be taken into account for research and development. [8]

Limited bandwidth: Bandwidth is known as the amount of data or information packets that are sent through an existing communication network. As VANET has no wireless infrastructure, there is a weakening in the signal due to electromagnetic interference resulting in a reduced bandwidth if compared to guided networks.

- Mobility: One of the main targets of wireless networks is to be able to move nodes within the network reception range; however, this brings as a consequence a restriction in mobility. The connection between nodes (vehicles) could last a few seconds causing problems in communication.

- Quality of service: QoS is a challenge in changing topologies as it is difficult to guarantee the resource reservation needed as it happens in guided networks. QoS in VANET is of utmost importance due to the use of video-conferencing and video-streaming extensions.

- Security: As there is no infrastructure and the channel of communication used is the air, it is more difficult to establish security measures becoming more vulnerable to external attacks.

\section{DSR (Dynamic Source Routing)}

The Dynamic Source Routing protocol was created in 1994 by researchers Johnson and Maltz. Still in its pilot phase, it can be found in the request for comments (RFC), number 4728 of the Internet Engineering Task Force (IETF). It is based on routing so the root node knows the hops needed to reach the destination port. It is a simple and efficient protocol designed specifically for wireless Ad-Hoc networks with several mobile nodes. Using DSR, the network is entirely self-organized and auto-configurable. It does not require any infrastructure or centralized management. [10]

These network nodes help forwarding the packets from one node to the next allowing multi-hop communication. Network nodes can move, get together or exit the network whenever is needed. The routing is determined automatically and managed by the DSR protocol.

Route Request (RREQ), Route Replies (RREP) and Route Errors (RERR) are the types of messages used to set up the routing. These messages are sent and received via the User Datagram Protocol (UDP). The information is stored in the cache memory of each node in the network. [11]

\section{AODV (AD-HOC DEMAND DISTANCE VECTOR)}

The Ad-Hoc Demand Distance Vector (AODV) was created in 1999 by Charles E. Perkins (Sun Microsystems) and Elizabeth M. Royer (University of California). This protocol is based on DSR and DSDV. All the corresponding information is recorded in the Request for Comments (RFC) number 3561 released in July 2003 on a trial basis and it belongs to the Internet Engineering Task Force (IETF). This is a reactive protocol so each node has a routing chart for the roads already known. [13]

To create this chart, the neighboring nodes are used first. Then, nodes can connect with distant nodes with a number of hops through other nodes along the way. One of the most important characteristics of AODV is the reduced

bandwidth consumption and CPU as packets are only sent on demand.

AODV uses a road discovery process in broadcast mode. It also supports unicast, multicast and uses messages such as Route Request (RREQ), Route Replies (RREP) and Route Erros (RERR). Just as the previous protocol, AODV also uses the mentioned messages to exchange information between source and destination ports. [15]

\section{SIMULATION}

The simulation area selected to apply these parameters is $750 \mathrm{mts}$. long and $700 \mathrm{mts}$. wide. Its length reaches from Jose Antonio Eguiguren St. to Lourdes St. and its width goes from Universitaria Ave. to Jose Joaquin de Olmedo St.

Figure 3 shows the selected area in Loja City. It covers 42 blocks where the nodes will be able to move and create networks following and analyzing the Quality of Service metrics QoS.

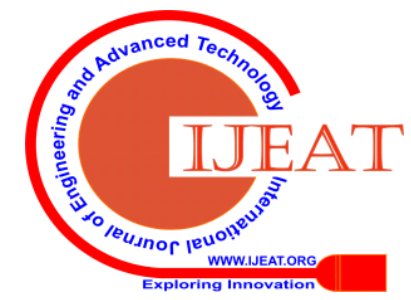




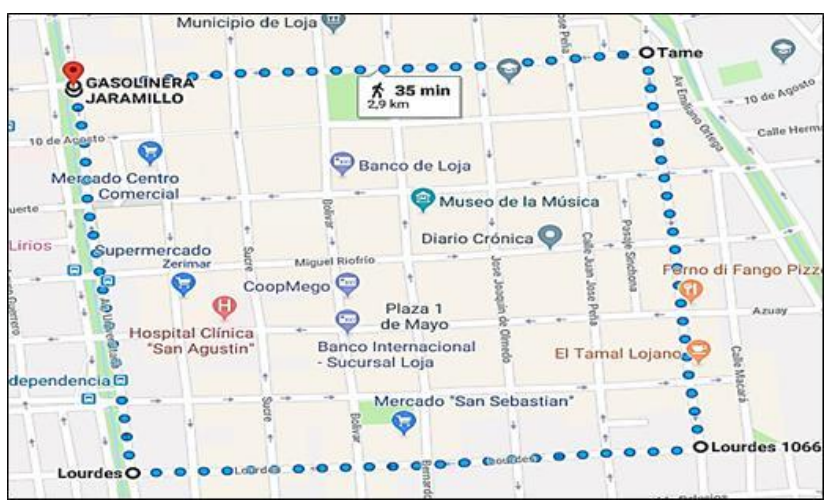

Figure 3 - Simulation Area

Throughput.- One of the selected metrics due to its importance in VANET analysis is the throughput. When comparing networks with high mobility, it is essential to get information about the efficiency in the process of packets arriving to destination ports, as well as the amount of loss data in the proposed scenario.

Delay.- The second metric chosen to compare and analyze is one of the most important ones in our network performance. It allows us to get information about the time a packet takes to go from the source node to the destination node. Having this information makes it possible to determine how far apart are the nodes and if the size of the area is appropriate for the amount of nodes moving throughout the network.

Jitter.- The third and last metric taken into account is known as Jitter and it is the variation in the packet transmission delays. This is very important as once the length of the delay is known, it is possible to deduce what caused it as that variation depends on the routes the nodes choose or an increase in the flow of each intermediary node in the network, which also varies according to each protocol and number of users.

To calculate the Throughput, the number of packets in bytes is multiplied by 8 to convert it into bits, then this amount is divided into the simulation time period obtaining the result in kbps.

$$
T h=\frac{\text { bytes } * 8}{T_{x} * 1000} \quad \text { Equation } 1
$$

Where:

Th $=$ Throughput

bytes $=$ Total bytes in each packet

The following formula is applied to obtain the delay, considering the time of arrival of each packet and this amount helps to calculate the difference between the current time and the time of arrival of the previous node.

$$
\begin{aligned}
& \qquad D l y=T_{A}-T_{p} \quad \text { Equation } 2 \\
& \text { Where: } \\
& \text { Dly = Delay } \\
& \boldsymbol{T A}=\text { Current simulation time } \\
& \boldsymbol{T P}=\text { Previous simulation time or Reception }
\end{aligned}
$$

The Jitter is obtained from the variation of the previous data, the delay, calculating the difference between the current delay and the previous delay. Then, the difference between the
$\boldsymbol{T} \boldsymbol{s}=$ Simulation time period

previous Jitter and this amount is divided into 16 and according to RFC 3393 it is used to reduce the noise.

$$
\text { fitt }=\frac{\left[\left(D l y_{A}-D l_{y_{p}}\right)-j i t t_{p}\right]}{16} \quad \text { Equation } 3
$$

Where:

$$
\begin{aligned}
& \text { Jitt }=\text { Jitter } \\
& \text { Dly } \boldsymbol{A}=\text { Current packet delay } \\
& \text { Dly } \boldsymbol{P}=\text { Previous packet delay } \\
& \boldsymbol{J i t t P}=\text { Previous packet Jitter }
\end{aligned}
$$

\section{DATA ANALYSIS}

\section{A. Scenario 1: 25 nodes}

The first scenario for the comparative study and analysis of the routing protocol comprises 25 nodes using the parameters shown in Table 1.

\section{TABLE 1 - MOBILITY PARAMETERS 25 NODES}

\begin{tabular}{|l|c|}
\hline \multicolumn{1}{|c|}{ Parameters } & Quantity \\
\hline Number of nodes & 25 \\
\hline Area $[\mathrm{m}]$ & $\mathrm{x}=750 \mathrm{y}=700$ \\
\hline Mobility model & Manhattan Grid \\
\hline Simulation duration time [s] & 200 \\
\hline Minimum speed $[\mathrm{km} / \mathrm{h}]$ & 10 \\
\hline Medium speed $[\mathrm{km} / \mathrm{h}]$ & 25 \\
\hline Maximum speed $[\mathrm{km} / \mathrm{h}]$ & 40 \\
\hline Horizontal blocks & 7 \\
\hline Vertical blocks & 6 \\
\hline
\end{tabular}

The following charts show the packets sent during the simulation (Fig. 4) and the route discovery of each node in this scenario (Fig. 5).

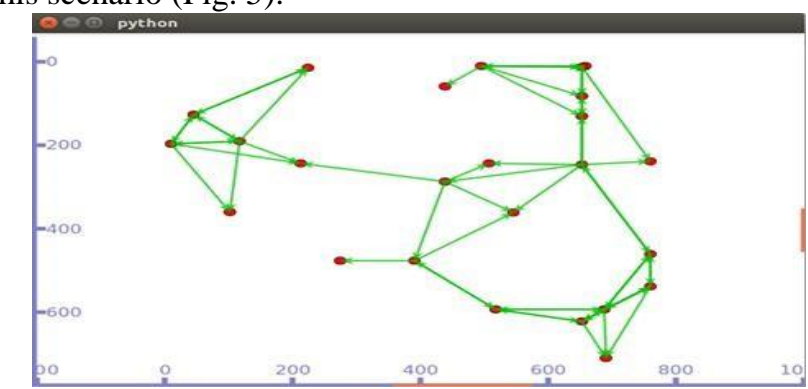

Figure 4 - Packets sent in a 25 nodes scenario

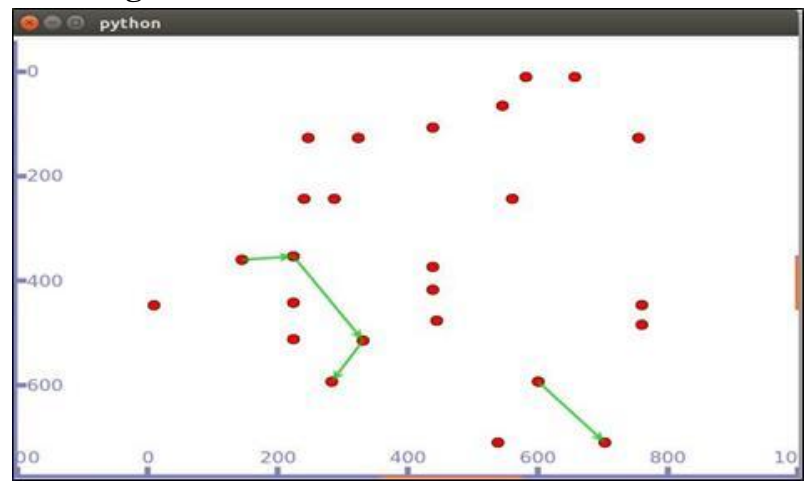

Figura 5 - Route discovery in a 25 nodes scenario

Published By:

Blue Eyes Intelligence Engineering

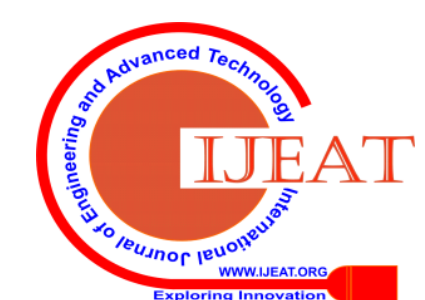




\section{THROUGHPUT}

Fig.6 shows the comparison of the first metrics, the throughput results. It reveals that in the 25 node scenario created in the Manhattan Grid model, the performance in AODV packet delivery is stable, but it is higher in DSR which means the DSR routing protocol performs better in a scenario with less nodes as the routes are stored in the header with no overload.

\section{THROUGHPUT}

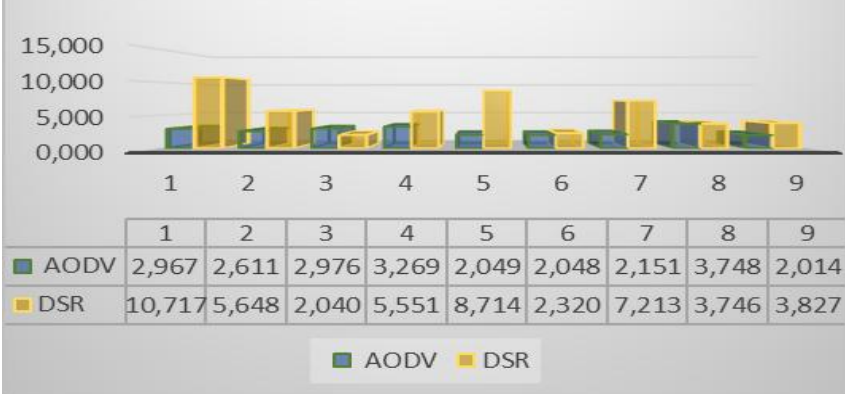

Figure 6- Throughput in a 25 node scenario

\section{DELAY}

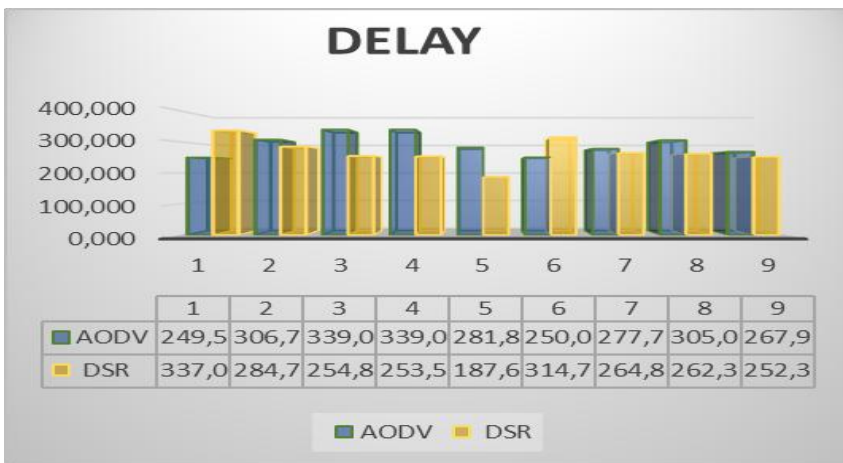

Figure 7- Delay in a 25 node scenario

For the first scenario, Fig. 7 shows the Delay comparison, indicating that the AODV protocol has a longer delay in delivery. With less nodes in a more extended area, there is a higher delay than in DSR due to the distance between nodes as AODV is constantly identifying new routes.

\section{JITTER}

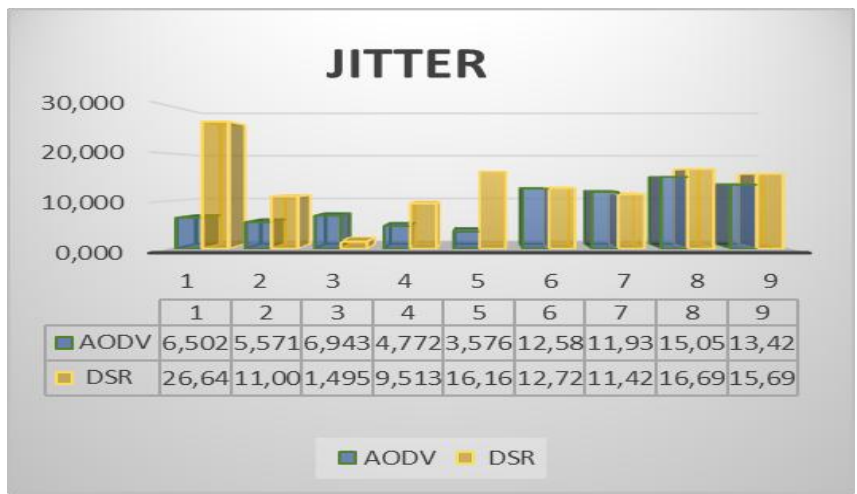

Figure 8 - Jitter in a 25 node scenario
Fig.8 shows Jitter metrics. As mentioned before, the AODV protocol has less delay variation. This protocol is constantly discovering new routes, which means it has more stability and convergence than DSR as there are many intermediary nodes generating new routes, having less delay variations as a result.

\section{B. Scenario 2: 50 nodes}

Table 2. MOBILITY PARAMETERS - 50 NODES

\begin{tabular}{|l|c|}
\hline \multicolumn{1}{|c|}{ Parameters } & Quantity \\
\hline Number of nodes & 50 \\
\hline Area $[\mathrm{m}]$ & $\mathrm{x}=750 \mathrm{y}=700$ \\
\hline Mobility model & Manhattan Grid \\
\hline Simulation duration time $[\mathrm{s}]$ & 200 \\
\hline Minimum speed $[\mathrm{km} / \mathrm{h}]$ & 10 \\
\hline Medium speed $[\mathrm{km} / \mathrm{h}]$ & 25 \\
\hline Maximum speed $[\mathrm{km} / \mathrm{h}]$ & 40 \\
\hline Horizontal blocks & 7 \\
\hline Vertical blocks & 6 \\
\hline
\end{tabular}

Likewise, fig.9 and fig. 10 show the distribution of the nodes in the packet delivery and route discovery scenario.

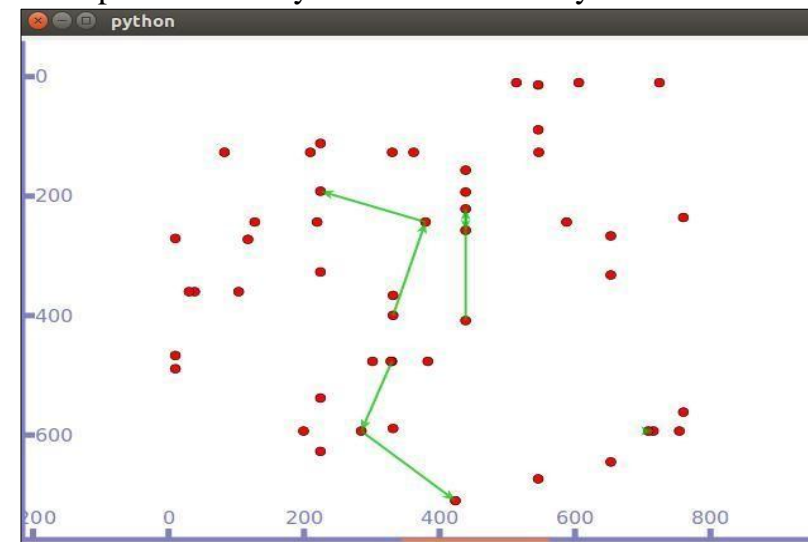

Figure 9- Packet delivery in a 50 node scenario

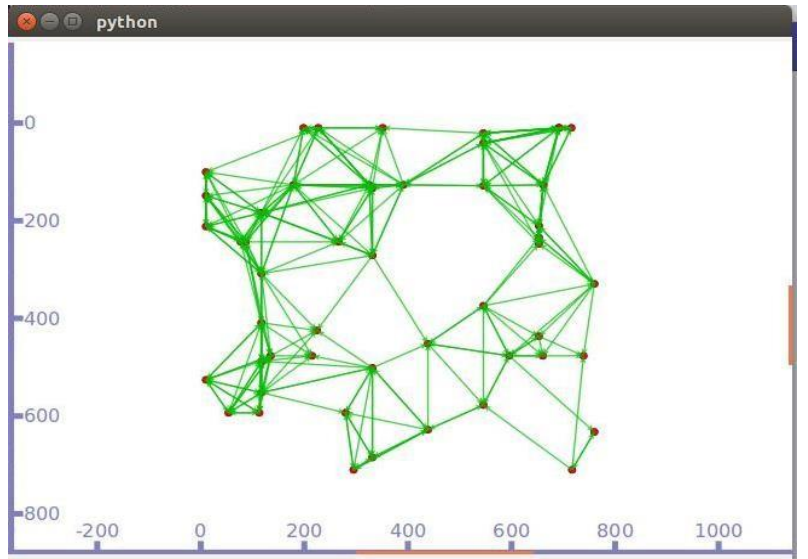

Figure 10- Route discovery in a 50 node scenario Throughput

Fig. 11 shows an improvement in the throughput of the AODV protocol in the 50 node scenario. As it has less number of nodes moving across the designated area,

Published By:

Blue Eyes Intelligence Engineering

\& Sciences Publication

(C) Copyright: All rights reserved.

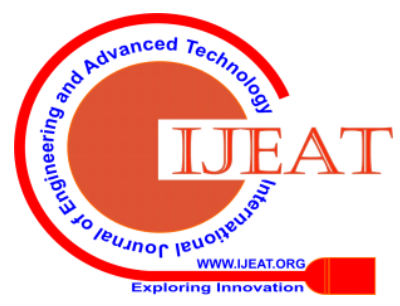


there is a less number of lost packets compared to DSR which uses one route from the beginning and as the nodes move further away, the packet loss is higher.

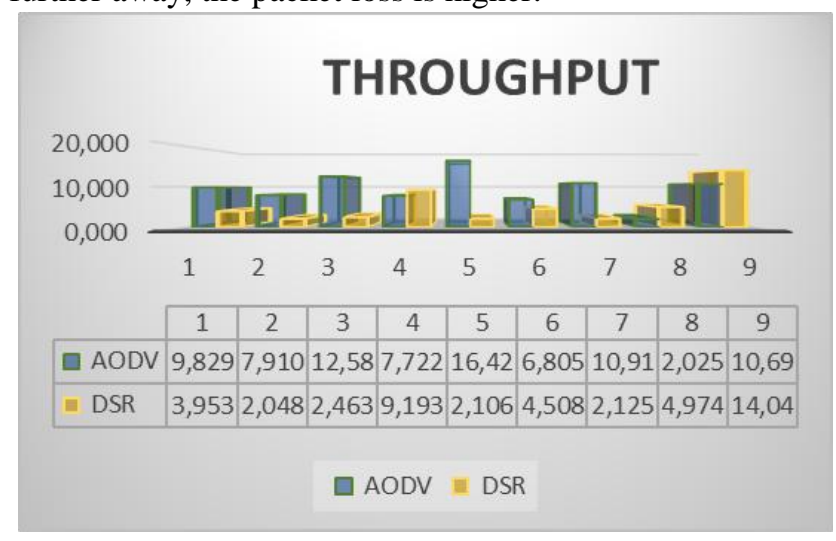

Figure 11. Throughput in a 50 node scenario

\section{DELAY}

In the second scenario, there is a little variation in the Delay in the DSR packet delivery compared to AODV. As shown in fig.12, the difference is minimum because DSR uses the same route from the emitting node onwards and as there are other nodes moving along there is a communication loss, having to start a new discovery in the source node.

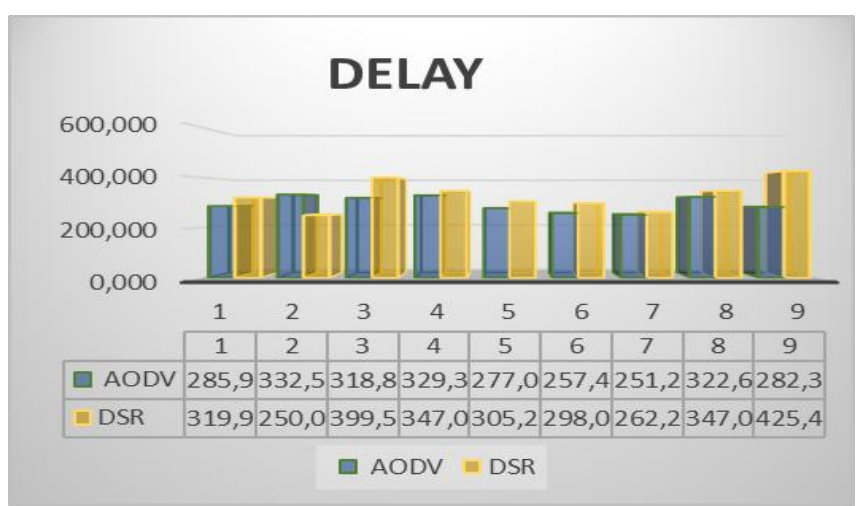

Figure 12. Delay in a 50 node scenario

\section{JITTER}

In Fig. 13, the third metric in the 50 node scenario shows that the AODV protocol is more stable and it has a higher degree of convergence as its Jitter is lower compared to DSR. A higher node density in the designated scenario and the use of one route only starting in the source node generate an overload and heavy traffic getting a higher percentage in the Delay variation in DSR.

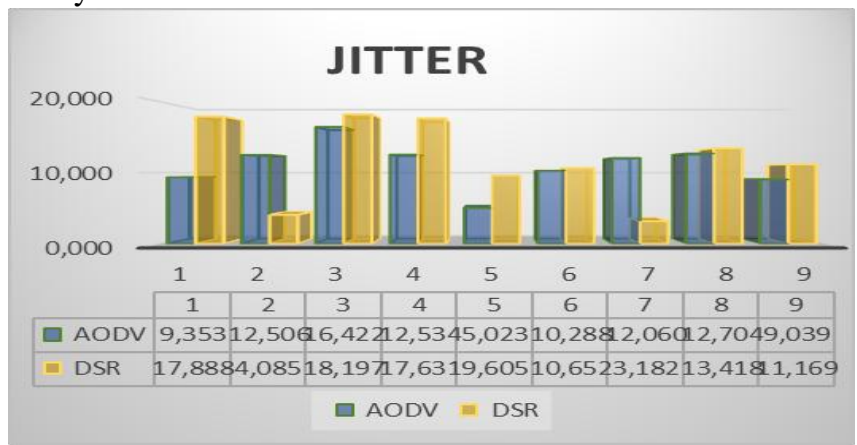

Figure 13. Jitter in a 50 node scenario

\section{Scenario 3: 100 nodes}

TABLE 3 MOBILITY PARAMETRES - 100 NODES

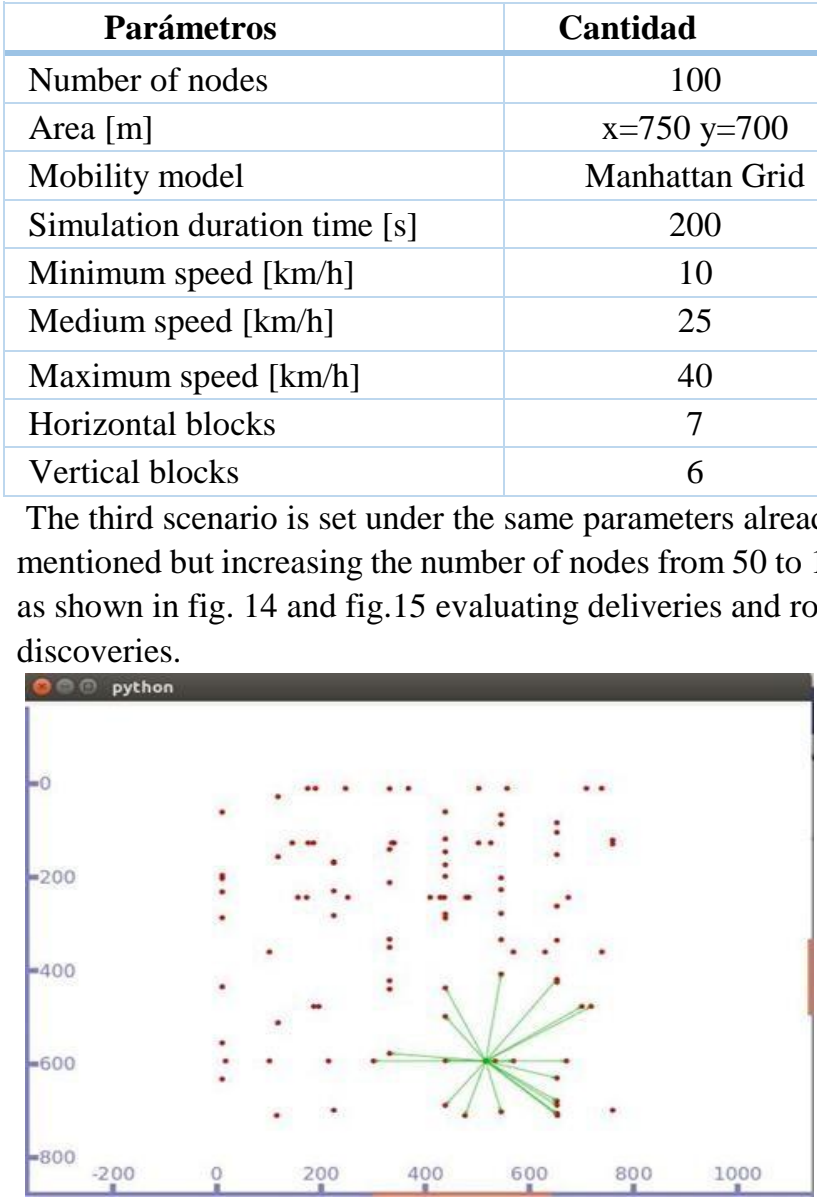

Figure 14. Packet delivery in a 100 node scenario

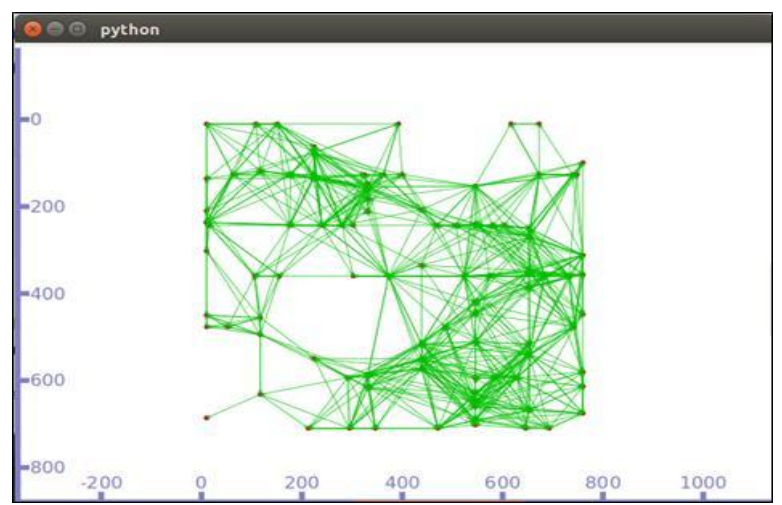

Figure 15. Route discovery in a 100 node scenario Throughput

Fig.16 shows the throughput results evaluated on this third scenario in a simulation with 100 nodes distributed along the selected area. The AODV protocol with these metrics performs better which means that when having a higher number of nodes, AODV becomes more efficient with more routes discovered and making it more stable. It's worth mentioning that the DSR protocol starts declining when the number of nodes or connections increases as it needs to place in the header the nodes needed from source and destination in a determined time frame causing buffer overflow in each node and packet loss.

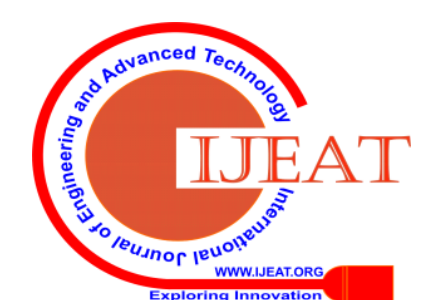




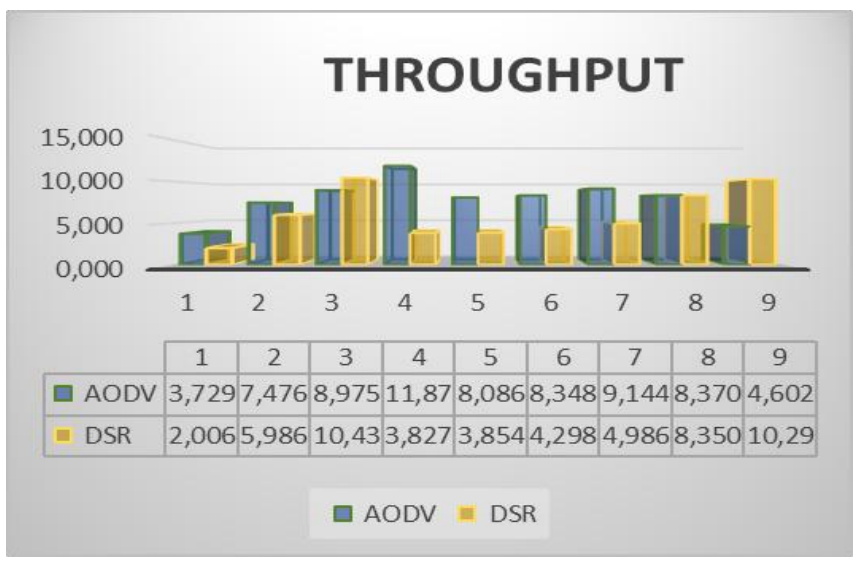

\section{Figure 16. Throughput in a 100 node scenario DELAY}

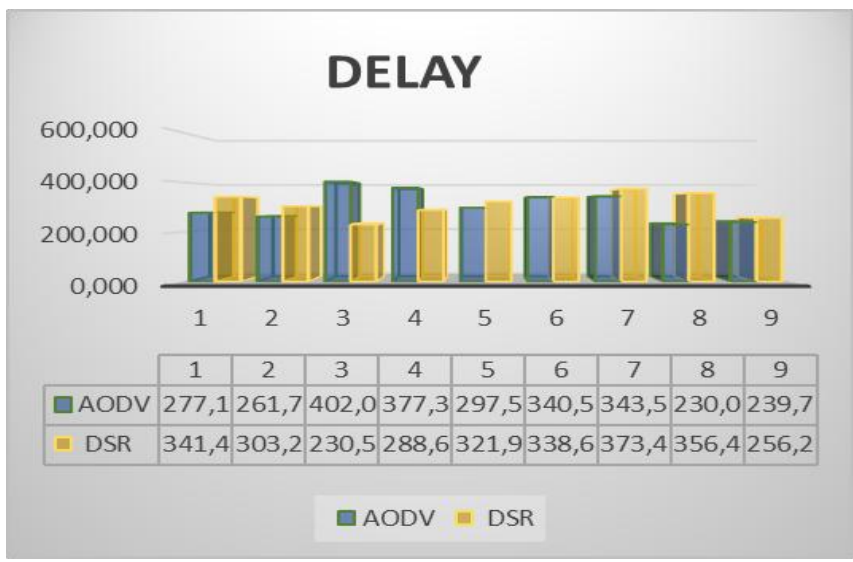

Figure 17. Delay in a 100 node scenario

Fig. 17 presents the data results gathered for the second metrics, the Delay on packet delivery. In this scenario, the Delay in the AODV protocol is higher compared to DSR. This is totally understandable as there are more nodes involved so AODV needs to discover new routes. As a result, there is a higher number of delays and also packet loss due to collisions caused by the high number of nodes. DSR experiences less delays as it has one route already established starting from the source.

\section{JITTER}

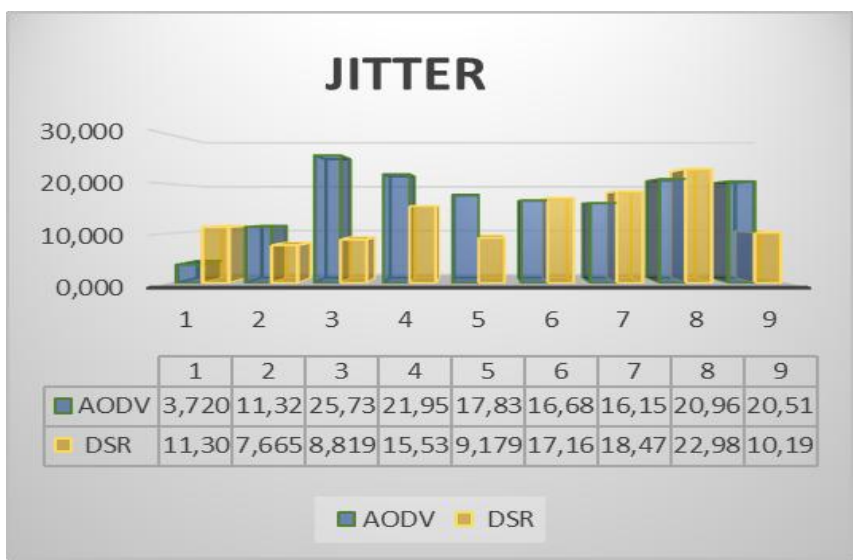

Figure 18. Jitter in a 100 nodes scenario

Fig. 18 shows the Jitter results in this scenario where AODV has more variation in the Delay as more routes are generated given the higher number of nodes causing more traffic and collisions. As a result, this protocol is unstable, and it has little convergence. This data depends on the number of nodes as well as in the distance between them in the simulation area.

\section{CONCLUSION}

In order to achieve the set targets, it is the utmost importance to use NS-3 software as it is a full-network simulator comprised by different modules. It also has a guide with information about the implemented networks and specifically the protocols tested here.

- The data collected during the simulations shows that Throughput, Delay and Jitter in AODV and DSR routing protocols vary according to the amount of nodes, mobility and the size of the area used in the network topology.

- In the study using the Manhattan Grid model, AODV and DSR protocols show similar results in the three proposed scenarios concluding that the DSR protocol has a better quality of service where there is less node density. In contrast, AODV is more efficient when there is a higher number of nodes as it is constantly discovering new routes. Besides this, AODV has less delay end-to-end as having a higher number of collisions, new routes are constantly being established in contrast with DSR which maintains only one route from source to destination.

- Following one of the study goals, the scenarios needed in the Manhattan Grid mobility model have been successfully created using Bonnmotion. This tool creates files that are compatible with the NS-2 software but with the help of several lines of code were imported to the NS-3 software used in this study.

- According to the data obtained in the three simulation scenarios and models, when the DSR routing protocol sends a delivery it should store the destination route and place it in the packet header. Having scenarios with an increase in the amount of nodes there is an overflow as having longer routes causes a considerable growth in the header size and routing tables resulting in packet loss and a decrease in quality of service (QoS)

- Based on the analysis and comparison of the quality of service (QoS) metrics in each scenario and model used in this study, it could be concluded that the AODV routing protocol performs better in high node density scenarios, differing from DSR which is stable in smaller scenarios. Therefore, AODV is the protocol to be taken into account in future field trials due to scalability, city growth, heavier traffic and apps increase.

\section{RECOMMENDATIONS}

In order to study and analyze the different routing protocols it is advisable to have information about the RFC applied to each protocol, computer networks, programming language $\mathrm{C}++$, free software, etc.

- To avoid problems during AODV and DSR simulations in VANETs, it is recommended to use stable versions of software such as Ubuntu 16.04 and NS-3 2.28 as their tools are documented and operating.

\section{Published By:}

Blue Eyes Intelligence Engineering \& Sciences Publication

(C) Copyright: All rights reserved.

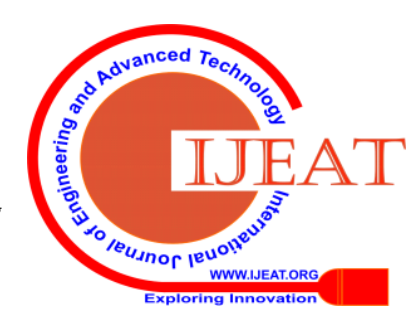


- It is important to pay special attention when getting quality of service metrics in the protocols as the different existing methods do not

work in AODV and DSR on the same way when sending packets which causes trouble getting data.

- It is also advisable to check if the mobility models chosen for the simulation in VANETs have libraries compatible with the NS-3 software or if they could be created using external tools so the metrics could be compared without any hassle.

\section{REFERENCES}

1 M. Frodigh y P. Larsson, "Formación de redes inalámbricas ad hoc-El arte de la formación de redes sin red", 2000.

2 J. Francisco, Hidalgo, "Estudio de viabilidad de la utilización de redes inalámbricas Ad-Hoc", 2008.

3 N. P. L. Marquez, "Performance Evaluation of Bandwidth- Aware Routing Protocol in Urban Scenarios for Vehicular Ad hoc NETworks", p. 141, 2014.

4 L. I. Lares, A. Díaz-ramírez, H. S. Hernandez, y V. Quintero, "Evaluacion de protocolos de encaminamiento para redes vehiculares Ad hoc", Congr. Int. Robótica y Comput. (CIRC 2015), pp. 26-31, 2015.

5 P. Caballero-gil y J. Molina-gil, "Gestión de Grupos en

6 VANETs : Descripción de Fases”, núm. September, 2014.

7 P. Fazio, F. De Rango, C. Sottile, P. Manzoni, y C. Calafate,

8 "A distance vector routing protocol for VANET environment with Dynamic Frequency assignment", en 2011 IEEE Wireless Communications and Networking Conference, 2011, pp. 1016-1020.

9 L. Hechavarria, "Impacto del tamaño de la ventana de contención (CW) del protocolo IEEE 802.11p en el desempeño de las Redes Ad-Hoc Vehiculares", Universidad Central “Marta Abreu ” de Las Villas, 2016.

10 S. Chirinos, "Evaluación de los protocolos de enrutamiento AODV y OLSR en redes VANET", 2013.

11. Fabián Sánchez Marín y R. Adriana Pineda Samacá, “Evaluación De Redes Vanet Orientada Al Tráfico Vehicular En La Ciudad De Bogotá. Evaluation of Networks Vanet Vehicular Oriented Traffic in the City of Bogota", 2016.

12. D. Johnson, Y. Hu, y D. Maltz, "The Dynamic Source Routing Protocol (DSR) for Mobile Ad Hoc Networks for IPv4", 2007.

13. J. J. Piles, "Uso de rutas cacheadas en el encaminamiento seguro basado en DSR", 2016.

14. G. Rodríguez, ““ Análisis y Simulación de protocolos de enrutamiento adecuados en diferentes escenarios para redes

15. AdHoc , mediante la herramienta Ns-3 "', Universidad Nacional de Loja, 2015.

16. C. Perkins, E. Belding-Royer, y S. Das, “Ad hoc On-Demand

17. Distance Vector (AODV) Routing Status", Santa Barbara, 2003.

18. M. G. Campos, "Evaluación de Protocolos de Encaminamiento Para Redes Vehiculares (VANET)", 2016.

19. P. A. Gómez, G. A. Posada, y M. A. Vallejo, "Evaluación del desempeño del protocolo de enrutamiento AODV para diferentes escenarios de redes de sensores inalámbricos", 2014.

20. T. Hirai y T. Murase, "Communication Method to improve QoS in V2X Communications in Crash Warning Application", vol. 1, núm. 5, pp. 1-6, 2018.

21. S. Olariu y M. A. C. Weigle, Vehicular networks : from theory to practice. CRC Press, 2009.

22. F. Cunha et al., "Data communication in VANETs : Survey,

23. applications and challenges", Ad Hoc Networks, 2016.

24. M. J. Andrade Tenén, "Estudio y simulación de redes heterogéneas vanet, con la variación de tecnología inalámbrica según la capacidad de usuarios en zonas urbanas de varios sectores de la ciudad", Universidad Politecnica Salesiana, Quito, 2017.

25. Torres, "ANÁLISIS DE LA CALIDAD DE SERVICIO

26. EN EL ENRUTAMIENTO DE LAS REDES MÓVILES

27. AD-HOC", Universidad Tecnica Particular de Loja, 2010.

28. [21] S. Boussoufa-lahlah, F. Semchedine, y L. Bouallouchemedjkoune, "Geographic routing protocols for Vehicular Ad hoc NETworks ( VANETs ): A survey”, Veh. Commun., vol. 11, pp. 20-31, 2018.
29. S. Chirinos, "Evaluación de los protocolos de enrutamiento AODV y OLSR en redes VANET", 2013.

30. J. I. Torres, "Implementación del protocolo de enrutamiento

31. GPRS para redes móviles en la herramienta NS.", Universidad Técnica Particular de Loja, 2018.

32. M. E. Palacios Morocho, "Implementación de un simulador de redes mediante software libre para el laboratorio de Telecomunicaciones del AEIRNNR", Universidad Nacional de Loja, 2017.

33. J. Sánchez, "Redes Vehiculares Aplicadas a la Movilidad Inteligente y Sostenibilidad Ambiental en Entornos de Ciudades Inteligentes", 2017.

34. M. Rondinone, "Enrutamiento Basado en Conectividad Multi-hop en Redes Ad-hoc Vehiculares", 2017.

35. L. Maygua, "Simulación de un mecanismo de control de potencia en AODV en función del número de vecinos usando cross layering en una MANET", Escuela Politecnica Nacional, 2017.

36. E. P. Vintimilla, "Simulación de protocolos de encaminamiento para la difusión de mensajes de alarma en redes vehiculares ad hoc mediante el uso de software libre", Universidad Politecnica Salesiana de Cuenca, 2016.

37. M. Carrión, "Analísis de la simulación de la diseminación de mensajes de emergencia en redes Vehiculares Ad-Hoc Mediante software libre", Universidad Politecnica Salesiana de Cuenca, 2016.

38. E. C. Eze, S. Zhang, E. Liu, y J. C. Eze, "Advances in Vehicular Ad-Hoc Networks ( VANETs ): Challenges and Road-map for Future Development 2 Overview of VANETs", 2016.

39. K. Matsumoto, "Data Uploading Control Method Based on Exchange of Metadata in VANET for On-demand Onboard Camera Picture Sharing System", 2018.

40. C. Perez, "Implementación del protocolo de encaminamiento", Universidad Politecnica de Cataluña, 2017.

41. G. Yan y D. Rawat, "Data Mining Intrusion Detection in Vehicular Ad Hoc Network”, núm. 7, pp. 1719-1726, 2014.

42. Fujiwara, "State space reduction techniques for model cheking of MANET protocolos", vol. 7, núm. 1, pp. 29-49, 2017.

\section{AUTHORS PROFILE}

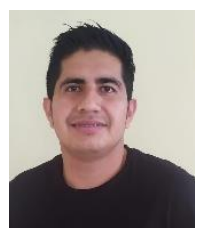

Cristian P. Saavedra Cañar Electronics and Telecommunications Engineer, Universidad Nacional de Loja, Ecuador, Department of Electronics and Telecommunications.

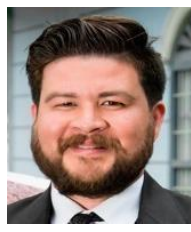

John J. Tucker Yepez Engineer specialist in communication networks and switching systems, State University of Belgorod Russia, Master in international sciences and diplomacy, Ecuador, Researcher at the Universidad Nacional de Loja, Department of Telecommunications.

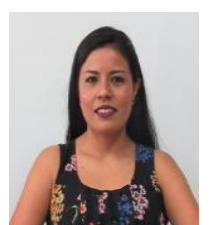

Heydi M. Roa López ESPOL Polytechnic University, Escuela Superior Politécnica del Litoral, ESPOL, Faculty of Natural Sciences and Mathematics, Campus Gustavo Galindo km 30.5 Vía Perimetral, P.O. Box 09-01-5863, Guayaquil, Ecuador

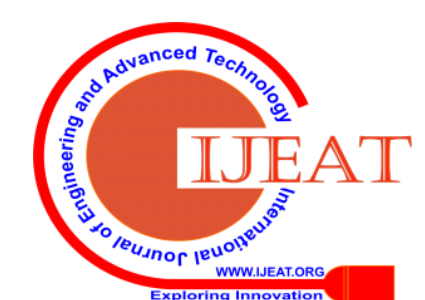

